\title{
PARTICIPACIÓN V REUNIÓN DE ANTROPOLOGÍA DE LA CIENCIA Y LA TECNOLOGÍA (V REACT), 20 AL 22 DE MAYO 2015, PORTO ALEGRE, BRASIL
}

La profundidad de la reflexión sobre la implementación de políticas, programas, acciones y movimientos sociales en Brasil es notable. La Quinta Reunión de Antropología de la Ciencia y la Tecnología, realizada en Porto Alegre entre los días 20 y 22 de mayo del 2015, fue un espacio donde compartimos con investigadores/as de distintas regiones del Brasil, reforzándonos la intuición de que una ola académica estrechamente implicada con la acción social sigue ganando altura por aquellas latitudes. Las múltiples negociaciones, traducciones y contradicciones insertas en cada microespacio donde "bajan" las políticas sociales, son mundos en sí mismos plagados de singularidad, pero que en su observación sistemática y "desde dentro" son capaces de revelar un conocimiento situado dialogante con otras singularidades. Es en la diversidad de temáticas que cruzan desde el rol de los “animales no humanos” en la vida contemporánea, pasando por las mutaciones en torno al cuerpo, la medicalización y las tecnologías, llegando hasta las implicaciones de los derechos con y para las ciencias de la vida, donde se observan las grandes líneas de fuga en torno a las problemáticas globales que habitan heterogéneamente lo local.

En ese espíritu de examen microscópico, nuestra investigación sobre los discursos predominantes y las exclusiones dentro de las zonas rurales del sur de Chile fue bien recibido, dando cuenta de tensiones que cruzan los limites nacionales, políticos y disciplinares: bajo la lucha entre la hegemonía y contrahegemonía discursiva hay heterogéneas voces que habitan en la praxis un relato de mundos paralelos, que se manifiestan sigilosamente y con encantos.

La actividad permitió vivir y sentir la experiencia de discursos entre actores diversos posicionándose en la discusión local, quienes recibieron retroalimentaciones detalladas y precisas que permitían avanzar en los caminos de diálogo, discusión y construcciones. Estas lecturas minuciosas de los diferentes ejercicios investigativos presentados, y que daban cuenta de distintos avances o niveles en los procesos de investigación, fue una de las cualidades más valoradas de este evento, en tanto permitió instalar cuestionamientos no percibidos por los equipos de investigación, ayudando a dar saltos hacia nuevos dominios y escenarios.

Fue interesante observar cómo una experiencia en un contexto particular, la ruralidad austral de Chile, presentada por un equipo multicultural y multidisciplinar -médico chileno, trabajadora social colombiana, psicóloga brasileña- hizo contraste con las cuestiones en boga en Brasil. No obstante, en la heterogeneidad de miradas y campos de actuación se pudo percibir la red de conversaciones que constituyen nuestra matriz latinoamericana.

Queda abierta la reflexión en tanto pretensiones disciplinares y desafíos para quienes transitamos por los dominios del campo investigativo, la invitación a construir y visualizar nuevas posibilidades desde otros paradigmas: convocatoria a la osadía de conocimientos, más allá de la rigidez disciplinar y de las epistemes modernizantes. La posibilidad de movernos y pensar lo impensable. 